\title{
The influence of environmental factors on water mite assemblages (Acari, Hydrachnidia) in a small lowland river: an analysis at different levels of organization of the environment
}

\author{
Andrzej Zawal ${ }^{1} \cdot$ Robert Stryjecki $^{2} \cdot$ Edyta Stępieńn $^{3} \cdot$ Edyta Buczyńska $^{2} \cdot$ \\ Paweł Buczyński $^{4} \cdot$ Stanisław Czachorowski $^{5} \cdot$ Joanna Pakulnicka $^{5} \cdot$ \\ Przemysław Śmietana ${ }^{6}$
}

Received: 22 March 2016/ Accepted: 21 December 2016/Published online: 10 January 2017

(C) The Author(s) 2017. This article is published with open access at Springerlink.com

\begin{abstract}
Research on the ecology of water mites in flowing water has focused mainly on analysis of factors directly affecting these organisms in the aquatic environment. The hypothesis of this study was that apart from factors acting within the aquatic environment, the formation of Hydrachnidia communities in lotic ecosystems may also be affected by factors acting in the terrestrial environment. The analysis was made at three different levels of organization of the environment: (1) landscape level (subcatchments, terrestrial environment), (2) macrohabitat level (sampling sites, aquatic environment) and (3) mesohabitat level (sampling sub-sites, aquatic environment). Some correlation was noted between certain species and some
\end{abstract}

Handling Editor: Junjiro N. Negishi.

Electronic supplementary material The online version of this article (doi:10.1007/s10201-016-0510-y) contains supplementary material, which is available to authorized users.

Robert Stryjecki

robstry@wp.pl

1 Department of Invertebrate Zoology and Limnology, University of Szczecin, Wąska 13, 71-415 Szczecin, Poland

2 Department of Zoology, Animal Ecology and Wildlife Management, University of Life Sciences in Lublin, Akademicka 13, 20-950 Lublin, Poland

3 Department of Plant Taxonomy and Phytogeography, University of Szczecin, Wąska 13, 71-415 Szczecin, Poland

4 Department of Zoology, Maria Curie-Skłodowska University, Akademicka 19, 20-033 Lublin, Poland

5 Department of Ecology and Environment Protection, University of Warmia and Mazury, Pl. Łódzki 3, 70-727 Olsztyn, Poland

6 Deparment of Ecology and Environmental Protection, University of Szczecin, Wąska 13, 71-415 Szczecin, Poland sub-catchment parameters. This may indicate a link between some landscape features (terrestrial environment) and the formation of water mite assemblages in the river. The low percentage for physicochemical parameters together in explaining the variance in occurrence of species, very low correlations between species and physicochemical parameters and the discrepancy in the grouping of sites in the case of faunal data and data on the physicochemical indicates that physicochemical factors had little influence on water mites. Taking into account all three levels of organization of the environment analyzed, we can say that at the landscape level we can find only indirect relationships between environmental factors and the fauna inhabiting the aquatic environment; at the macrohabitat level the description of Hydrachnidia is more precise but still of a general nature. Only analysis at the mesohabitat level fully explains the specific character of Hydrachnidia assemblages.

Keywords River ecosystem - Landscape - Macrohabitats · Mesohabitats · Environmental parameters

\section{Introduction}

The Hydrachnidia (water mites) are one of the most ubiquitous components of the lotic communities in terms of both abundance and species richness (Di Sabatino et al. 2000, 2008). Research on the ecology of these mites in flowing water has focused mainly on analysis of factors directly affecting these organisms in the aquatic environment (Cicolani and Di Sabatino 1991; Gerecke and Schwoerbel 1991; Böttger and Martin 1995; Martin 1996; van der Hammen and Smit 1996; Martin 1997; Smit and van der Hammen 2000; Bagge 2001; Dohet et al. 2008; Boyací 
et al. 2012; Goldschmidt 2016). This is understandable, as at the deutonymph and adult stages water mites are absolute hydrobionts. It should be remembered, however, that the developmental cycle of most species includes a parasitic phase outside the aquatic environment, as phoretic larvae of water mites living on the larvae and pupae of aquatic insects transfer to their adult forms and parasitize them outside the aquatic environment (Böttger 1976; Di Sabatino et al. 2000; Smith et al. 2001).

The terrestrial environment is usually ignored in studies of aquatic organisms, despite the fact that it can be an essential component of population dynamics and community structure in some aquatic taxa (Delettre et al. 1992; Delettre and Morvan 2000; Galic et al. 2013). Most work considering the effects of landscape structure on biodiversity and spatial distribution of various organisms has been devoted mainly to terrestrial organisms (see Delettre 2005). But not only terrestrial animals are affected by landscape dynamics: landscape structure and land use influence aquatic habitats and, consequently, aquatic invertebrate and vertebrate communities (Richards and Host 1994; Richards et al. 1996; Weigel et al. 2003; Diana et al. 2006; Miserendino and Masi 2010; Miserendino et al. 2011; Epele et al. 2012). For example, the possible influence of terrestrial landscape structure on the spatial distribution of adult Chironomidae emerging from water bodies was investigated by Delettre and Morvan (2000). One of the conclusions of this research was that the terrestrial environment is an essential component of population dynamics and community structure in aquatic Chironomidae. As part of the life cycle of water mites takes place outside the aquatic environment, it can be assumed that the formation of particular Hydrachnidia assemblages in a given lotic ecosystem may also be influenced by factors outside the aquatic environment affecting the hosts of water mite larvae, i.e., flying insects (e.g., Chironomidae).

The hypothesis of this study was that apart from factors acting within the aquatic environment (macro- and mesohabitat levels), the formation of Hydrachnidia communities in lotic ecosystems may also be affected by factors acting in the terrestrial environment (landscape level) (see Fig. 1).

It was assumed that environmental factors acting at the level of the landscape influence water mites indirectly by affecting their food base, predators and hosts of water mite larvae (aquatic insects), but also by determining the hydrological characteristics of the river. At this level it is most difficult to find relationships between the variables analyzed and Hydrachnidia assemblages because of the vast complexity of the system analyzed. At the macrohabitat level, variables affect the fauna more directly and thus relationships between habitat characteristics and a particular composition of fauna can be more precisely determined. At the mesohabitat level the variables act in an

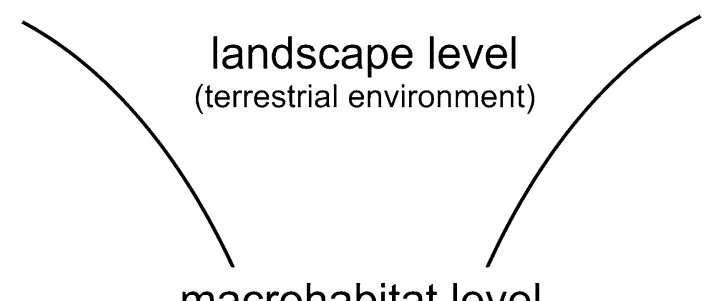

macrohabitat level

(aquatic environment)

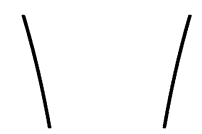

mesohabitat level

(aquatic environment)

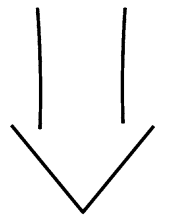

water mite assemblages

Fig. 1 Environmental factors affecting the formation of water mite assemblages in the river at three different levels of organization of the environment

even more precise manner, affecting the presence or absence of particular species (Fig. 1).

The aim of the study was to determine the effect of selected environmental and habitat factors acting at different levels of organization of the environment on the formation of Hydrachnidia assemblages in a small lowland river. The analysis included the effect of factors acting at the level of the landscape (sub-catchments), the level of the macrohabitat (sampling sites) and the level of mesohabitat (sampling sub-sites).

\section{Materials and methods}

\section{Study area, sites and field work}

The Krapiel is a small (length about $70 \mathrm{~km}$ ) lowland coastal river situated in northwestern Poland. The Krapiel has its source in Chociwiec Lake $\left(53^{\circ} 27^{\prime} 46.214^{\prime \prime} \mathrm{N}\right.$, $\left.15^{\circ} 20^{\prime} 52.503^{\prime \prime} \mathrm{E}\right)$ and empties into the Ina River $\left(53^{\circ} 19^{\prime} 08^{\prime \prime} \mathrm{N}, 15^{\circ} 03^{\prime} 07^{\prime \prime} \mathrm{E}\right)$. It has a diversified character: next to stretches with a rapid current and a bottom of stones and gravel, there are stretches with a slower water flow and a sandy or muddy bottom, as well as large marginal pools. The river flows through a variety of landscape structures: forests (hornbeam and oak, riparian forests and alder carrs), reeds and sedges, meadows, pastures, and urbanized areas. The valley contains floodplains and many oxbow lakes. 
Also present are numerous springs, predominantly helocrenes. The water bodies of the river valley occur in various landscape structures: dense forest complexes, small, isolated forested areas and open land. For most of its course the water quality of the Krapiel is of class I or II (Zawal 2014, unpublished).

The research covered the entire length of the river: 13 study sites (K1-K13) were established along the river (Fig. 2). For study sites we use alternatively a term 'macrohabitat' in the meaning 'a habitat of sufficient extent to present considerable variation of environment, contain varied ecological niches, and support a large and usually complex flora and fauna' (Merriam-Webster Dictionary 2014). At each of the 13 sites (macrohabitats) samples were collected from several sub-sites (K1/1, K1/2, K1/3 etc.). For sub-sites we use alternatively a term 'mesohabitat.' The term mesohabitat refers to visually varied habitats that can be recognized subjectively by their physical similarity (e.g., a sandbank, a gravel bank or a particular plant community). This term introduces a dimension of scale and should be distinguished from microhabitats (e.g., a leaf stem or the surface of a stone) and macrohabitats (e.g., entire fragments of water bodies) (Armitage and Prado 1995). The number of mesohabitats taken into account resulted from the spatial differentiation of the particular site and was as follows: two mesohabitats at sites $\mathrm{K} 4, \mathrm{~K} 9$ and $\mathrm{K} 12$, three at sites $\mathrm{K} 2, \mathrm{~K} 8$ and $\mathrm{K} 11$, four at $\mathrm{K} 3, \mathrm{~K} 5$, $\mathrm{K} 7, \mathrm{~K} 10$ and $\mathrm{K} 13$ and five mesohabitats at K1 and K6. Altogether there were 45 sub-sites distributed in such a way as to cover all habitat types in which water mites occurred. A detailed list of sites (macrohabitats) and subsites (mesohabitats) is given in Online Resource 1 in the Electronic supplementary material (ESM). Fieldwork was conducted from April to October 2010. Samples were collected once a month, in the middle of each month. On each sampling date and in each mesohabitat three sub-

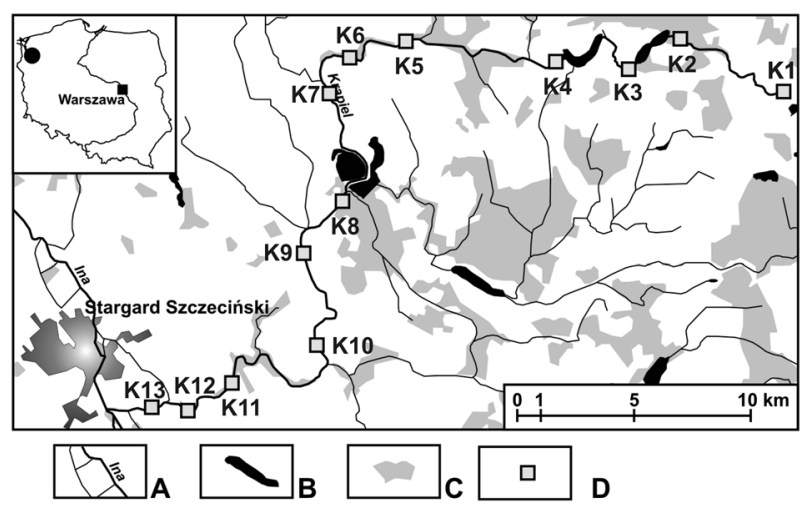

Fig. 2 Location of the sampling sites: $A$ rivers, $B$ lakes and fish ponds, $C$ forests and $D$ sampling sites (one sampling site in each subcatchment K1-K13). The direction of flow is from K1 to K13 samples were collected for representativeness. Each sampling consisting of ten sweeps was taken using a kick-net sampler with 300- $\mu \mathrm{m}$ mesh size and covered an area of about $0.5 \mathrm{~m}^{2}$, so the samples can be regarded as semiquantitative. In some months samples from some sites and/ or sub-sites were not collected because of hydrological conditions (very high or very low water level). A total of 810 samples were collected.

The catchment basin of the Krapiel River was divided into 13 sub-catchments in such a way that each two adjacent sites (K1-K2, K2-K3, etc.) formed the boundaries of one sub-catchment. Each of 13 sub-catchments corresponded to a particular study site (sub-catchment 1 for study site $\mathrm{K} 1$, sub-catchment 2 for study site $\mathrm{K} 2$, etc.). The following basic parameters at the landscape level were measured and described for each sub-catchment: combined surface area of the sub-catchment of all sampling sites from the source to the site, surface area of the sub-catchment of each site, the length of the boundaries of the sub-catchment, roughness (Ra) (Jenness 2004), Contagion Index (C) (McGarigal and Marks 1995), river gradient and distance from the source as well as the surface area of patches of different types present in the sub-catchment (forests, fields, swamps, built-up areas, meadows, shrubs, barren areas and water bodies) and their average distance from the river. In total 23 parameters at the landscape level were analyzed, and their values are given in Table 1.

Temperature, $\mathrm{pH}$, electrolytic conductivity and dissolved oxygen content were measured with an CX-401 multifunction meter (Elmetron, Zabrze, Poland), water flow using a SonTek acoustic FlowTracker flowmeter (SonTek, San Diego, USA), BOD 5 by Winkler's method, insolation with a CEM DT-1309 light meter (Merazet, Poznań, Poland) and the remaining parameters $\left(\mathrm{NO}_{3}, \mathrm{NH}_{4}\right.$, $\mathrm{PO}_{4}, \mathrm{Fe}$, turbidity and hardness) with a Slandi LF205 photometer (Slandi, Michałowice, Poland). Three measurements were performed each time, and the median was used for further analysis. In total 11 parameters at the macrohabitat level were analyzed, and their values are given in Table 1.

Parameters characterizing individual mesohabitats (velocity, insolation, degree of aquatic plant cover-plants, and substrate type and structure: organic, mineral, mean sediment grain size- $-\mathrm{M}$, and sediment sorting-W) were measured and described. Vegetation cover was determined on a scale of 0-5 as follows: 0-complete lack of vegetation at sampling site, $1-1-10 \%$ bottom cover by plants, $2-11-30 \%$ bottom cover, 3-1-50\%, 4-51-75\% and 5-76-100\%. The degree of bottom cover by vegetation was estimated visually. In total seven parameters at the mesohabitat level were analyzed, and their values are given in Table 1. 
Table 1 Values for analyzed parameters
Min Max

Parameters measured at the landscape level (parameters of the sub-catchments)

Combined surface area of the sub-catchment from the source to individual sites (as \% of total catchment area of the river)

Surface area of the sub-catchment of each site (as \% of total catchment area of the river) $\quad 0.77 \quad 30.4$

Length of catchment boundaries (in kilometers)

$12.4 \quad 107.6$

Roughness (Ra)

$9.2 \quad 24.4$

Contagion index $(C)$

$1.5 \quad 2.7$

River gradient (\%o)

Distance from the source of individual sub-catchments (in $\mathrm{km}$ )

$0.1 \quad 4.8$

Forests (as \% of the area of the sub-catchment)

$2.1 \quad 64.3$

Fields (as $\%$ of the area of the sub-catchment)

Swamps (as \% of the area of the sub-catchment)

$23.7 \quad 80.9$

Built-up areas (as \% of the area of the sub-catchment)

Meadows (as \% of the area of the sub-catchment)

Shrubs (as \% of the area of the sub-catchment)

Barren areas (as \% of the area of the sub-catchment)

$0.0 \quad 0.7$

Water bodies (as \% of the area of the sub-catchment)

$0.0 \quad 1.8$

$0.04 \quad 4.8$

Forests-distance from the river (in $\mathrm{km}$ )

$0.0 \quad 2.6$

Fields-distance from the river (in $\mathrm{km}$ )

$0.0 \quad 3.1$

Swamps-distance from the river (in $\mathrm{km}$ )

Built-up areas-distance from the river (in $\mathrm{km}$ )

$0.0 \quad 1.5$

Meadows-distance from the river (in $\mathrm{km}$ )

$0.0 \quad 2.2$

Shrubs-distance from the river (in $\mathrm{km}$ )

Barren areas-distance from the river (in $\mathrm{km}$ )

$0.0 \quad 2.7$

$0.0 \quad 1.5$

$0.0 \quad 1.6$

Water bodies-distance from the river (in $\mathrm{km}$ )

$0.0 \quad 2.6$

Parameters measured at the macrohabitat level (hydrochemical parameters of water)

Water temperature $\left({ }^{\circ} \mathrm{C}\right)$

$6.4 \quad 25.1$

$\mathrm{pH}$

$5.55 \quad 9.80$

Conductivity $\left(\mu \mathrm{S} \mathrm{cm}^{-1}\right)$

Dissolved oxygen $\mathrm{O}_{2}\left(\mathrm{mg}^{-1}\right)$

$65 \quad 305$

$\mathrm{BOD}_{5}\left(\mathrm{mg}^{-1}\right)$

$1.1 \quad 14.9$

$0.0 \quad 8.5$

$\mathrm{NH}_{4}\left(\mathrm{mg} \mathrm{l}^{-1}\right)$

$0.1 \quad 3.0$

$\mathrm{NO}_{3}\left(\mathrm{mg} \mathrm{l}^{-1}\right)$

$0.2 \quad 8.8$

$\mathrm{PO}_{4}\left(\mathrm{mg} \mathrm{l}^{-1}\right)$

$0.1 \quad 1.0$

$\mathrm{Fe}\left(\mathrm{mg} \mathrm{l}^{-1}\right)$

Solid concentration $\left(\mathrm{mg} \mathrm{l}^{-1}\right)$

$0.0 \quad 1.7$

$0.0 \quad 304$

Hardness $\left(\mathrm{mg}^{-1}\right)$

Parameters measured at the mesohabitat level (sediments and other parameters)

Organic sediments $(\%)$

$0.0 \quad 55.5$

Mineral sediments (\%)

$0.0 \quad 100.0$

Mean sediment grain size- $M$ (in millimeters)

$0.02 \quad 2.79$

Sediment sorting- $W$

$0.53 \quad 2.3$

Aquatic plant cover (on a scale from 0 to 5 )

Insolation (\%)

$0 \quad 5$

$0.0 \quad 100.0$

Water flow $(\mathrm{m} / \mathrm{s})$ 


\section{Laboratory work}

Bottom sediment analysis included determination of grain size and content of organic and mineral matter. Samples were collected by hand using a container with a capacity of 11. The Krumbein scale was used in the granulometric analysis, with grain size $(d)$ in $\mathrm{mm}$ expressed in phi units $(\varphi)$, where:

$\varphi=-\log _{2} d(\mathrm{~mm})$

The following calculations were made: mean grain size (graphic arithmetic mean), i.e., mean diameter $M=(\varphi$ $16+\varphi 50+\varphi 84$ ) $/ 3$, and sediment sorting (graphic standard deviation), which is a measure of the dispersion of grain diameter values: $\left.W=\left[\begin{array}{llll}\varphi & 84-\varphi & 16\end{array}\right) / 4\right]+[(\varphi$ $95-\varphi$ 5)/6.6].

Individual sediment samples were freeze-dried using a Christ Alpha 1-2 LD Freeze Dryer (Martin Christ Gefriertrocknungsanlagen $\mathrm{GmbH}$, Osterode am Harz, Germany), and then organic matter was removed from each sample by heating the sample in a Nabertherm High-Temp Muffle Furnace at $550{ }^{\circ} \mathrm{C}$ (Nabertherm $\mathrm{GmbH}$ ) to obtain a solid mass. In this manner the percentages of mineral and organic matter were determined.

\section{Statistical analyses}

Similarities between parameters were determined using BIODIVERSITY PRO v.2 software (McAleece et al. 1997). The Euclidian distance formula was used for abiotic parameters (parameters of the sub-catchment and physical and chemical properties of water) and the Bray-Curtis formula for faunal similarities (water mite fauna). The group-average clustering method was used.

The detrended correspondence analysis (DCA) between the composition of water mite taxa and different subcatchment parameters showed that the length of gradient represented by the first ordination axis equaled 4.893, proving that the species realized the full Gaussian spectrum, which justified conducting the direct ordination analyses of the canonical correspondence analysis (CCA) type in order to identify relations between the occurrence of species and different sub-catchment parameters taken into account. The significance of the effect of respective environmental parameters on the diversity of species composition was determined using stepwise variable selection $(p \leq 0.05)$. Monte Carlo test with 499 permutations was conducted in order to pinpoint the most significant variables.

Significance of differences in the abundance of particular species in macrohabitats was tested by non-parametric analysis of variance (Kruskal-Wallis test), and a nonparametric Spearman rank correlation $\left(r_{\mathrm{S}}\right)$ was used to calculate correlations. Statistica 10.0 software was used for calculation.

\section{Results}

A total of 9375 water mite individuals were caught with 116 species belonging to 28 genera and 19 families (Table 2, Online Resource 2 in the ESM).

\section{Landscape level}

Figure $3 \mathrm{a}$ presents a dendrogram grouping the sub-catchments of individual sampling sites (K1-13). Three clusters can be seen. The first cluster consists of the sub-catchments of sites situated in the upper course of the river (K1-K5). The greatest similarity within this aggregation, between the sub-catchments of sites K3 and K4, was 99.3\%. The next group consists of the sub-catchments of the sites located in the middle course of the river (K6-K10). The greatest similarity within this cluster was noted between the subcatchments of sites K6 and K7 (98.6\%). The third aggregation is composed of the sub-catchments of the sites in the lower course of the river (K11-K13). Within this cluster the greatest similarity was noted between the sub-catchments of sites $\mathrm{K} 12$ and K13 $(99.6 \%)$. The main subcatchment parameters grouping the sites were distant from the source, surface area of the sub-catchment and the river gradient in this sub-catchment area.

Figure 4 presents relationships between Hydrachnidia fauna and selected sub-catchment parameters (only statistically significant correlations are presented). Six variables together explain $29.3 \%$ of the total variance in the occurrence of species. In the upper right-hand corner of the diagram we can see a group of species closely associated with the parameter 'shrub area.' This group includes standing water species of the genera Limnesia [L. fulgida Koch, 1836, L. maculata (Müller, 1776) and L. undulatoides Davids, 1997), Piona (P. coccinea (Koch, 1836)] and Arrenurus [A. batillifer Koenike, 1896, A. bruzelii Koenike, 1885, A. cuspidator (Müller, 1776), A. globator (Müller, 1776), A. integrator (Müller, 1776), A. maculator (Müller, 1776) and A. tubulator (Müller, 1776)]. Another group of species is associated with the parameter 'river gradient' (lower right-hand corner of the diagram). This group includes rheobiontic species (e.g., Sperchonopsis verrucosa (Protz, 1896) and Atractides nodipalpis Thor, 1899) and rheophilic species (Hygrobates setosus Besseling, 1942), but also species preferring marginal pools (Hygrobates nigromaculatus Lebert, 1879). The third group of species was associated with several sub-catchment parameters ('catchment area,' 'river area,' 'distance to forest' and 'distance to source'), the most important of 
Table 2 Number of water mite specimens and species collected at each site in the Krạpiel River

\begin{tabular}{lrrrrrrrrrrrrrr}
\hline Study site & K1 & K2 & K3 & K4 & K5 & K6 & K7 & K8 & K9 & K10 & K11 & K12 & K13 & Total \\
\hline Specimens & 15 & 11 & 13 & 30 & 164 & 638 & 1425 & 470 & 523 & 2761 & 855 & 382 & 2088 & 9375 \\
Species & 6 & 5 & 2 & 14 & 18 & 28 & 53 & 44 & 31 & 36 & 34 & 27 & 31 & 116 \\
\hline
\end{tabular}

K1-K13-study sites (macrohabitats) which was 'distance to source.' The most abundant species in this group were Torrenticola amplexa (Koenike, 1908), T. brevirostris (Halbert, 1911) and Sperchon clupeifer Piersig, 1896. These species occurred in very high numbers at site K10 (Online Resource 2 in the ESM).

\section{Macrohabitat level}

Substantial differences were noted in the number of individuals and species caught at different sampling sites (macrohabitats) (Table 2). The differences in the number of individuals were statistically significant (Kruskal-Wallis test: $H(12, N=396)=51.75947 p<0.001)$.

Figure $3 \mathrm{~b}$ shows the faunal similarities between sampling sites. Faunistic similarity between sites ranged from 0.0 to $49.03 \%$ (Table 3). The highest similarity of fauna was noted between sites K11 and K13 (49.03\%), followed by sites $\mathrm{K} 6$ and $\mathrm{K} 7(47.76 \%)$ and sites $\mathrm{K} 11$ and $\mathrm{K} 12$ $(42.12 \%)$. A tendency can be seen for water mite assemblages from successive sites along the length of the river to be grouped together (e.g., a cluster including sites K1, K3 and $\mathrm{K} 4$; a pair $\mathrm{K} 6-7$, a cluster including sites $\mathrm{K} 11-13$ ). The fauna of site K2 clearly stands apart.

Figure 5 presents relationships between the distribution of water mite fauna and physicochemical parameters (only statistically significant correlations are presented). Six variables $\left(\mathrm{pH}\right.$, temperature, $\mathrm{BOD}_{5}, \mathrm{O}_{2}, \mathrm{NH}_{4}$ and $\mathrm{NO}_{3}$ ) explain together a total of $20.7 \%$ of the total variance in the occurrence of species. On the right side of the diagram are species characteristic of standing water bodies, mainly of the genus Arrenurus. Their distribution in the river was not associated with any of the analyzed physicochemical parameters. On the left, the majority of species are associated with rheocoenoses and belong to the genera Torrenticola, Sperchon, Atractides and Lebertia. Of the six statistically significant parameters influencing the distribution of fauna, the influence of $\mathrm{pH}$ was greatest, but the correlations between particular species and $\mathrm{pH}$ were very low and in most cases statistically insignificant (Table 3). Apart from $\mathrm{pH}$, the parameter having the greatest influence on the character of the fauna was temperature, but as in the case of $\mathrm{pH}$, the correlations between water temperature and particular species were very low and in most cases statistically insignificant.

Figure 3c shows similarities between the physicochemical parameters of the water at different sampling sites (macrohabitats). Three clusters are visible in the diagram. Cluster 1 groups sites from the lower course of the river (K8-K12), but also the first two sites (K1 and K2). Cluster 2 includes sites situated in the middle course of the river (K5-K7), but also one site from the lower reaches (K11). Cluster 3 contains two sites from the beginning of the course of the river (K3 and $\mathrm{K} 4$ ), but also the last site along its course (K13).

\section{Mesohabitat level}

Figure $3 \mathrm{~d}$ shows the faunal similarities between sub-sites (mesohabitats). For greater clarity, only similarities above $60.0 \%$ are shown in the diagram. Faunistic similarity values between sub-sites ranged from $0.0 \%$ to $73.93 \%$ (Table 3). The highest similarity of fauna was noted between sub-sites K12/1 and K13/2 (73.93\%). The habitat characteristics linking these two sub-sites were substrate type (sandy) and slow water flow (see Online Resource 1 in the ESM). The second highest faunistic similarity was noted between sub-sites K10/3 and K11/2 (73.45\%). In both sub-sites the substrate was sandy, but the water flow in them was different-slow at sub-site K10/3 and fast at subsite K11/2 (Online Resource 1 in the ESM). High faunistic similarity was also observed between sub-sites within the same site (no. K7/2-K7/3, K6/1-K6/4 and K10/2-K10/4), but these values were lower than for similarity between sub-sites from different sites (Fig. 3d).

Figure 6 presents relationships between water mite distribution and environmental parameters measured at mesohabitat level. Seven variables used in the ordination explain $19.1 \%$ of the total water mite species variance. Three of them (velocity, plants and insolation) were statistically significant and explained $18.1 \%$ of the total variance in the occurrence of species (velocity-6.6\%, plants-5.8\% and insolation-5.7\%). In the upper lefthand quarter of the diagram species whose distribution was most determined by current velocity are grouped together. The species associated with this environmental factor were Torrenticola brevirostris, T. amplexa, Sperchon clupeifer, Hygrobates calliger Piersig, 1896, Lebertia pusilla Koenike, 1911, and Atractides nodipalpis (Fig. 6). The species most strongly associated with current velocity was Torrenticola amplexa $\left(r_{\mathrm{S}}=0.49, p=0.001\right)$. All these species were caught in the highest numbers in the mesohabitats at site K10, with well-developed lotic zones 
(a)

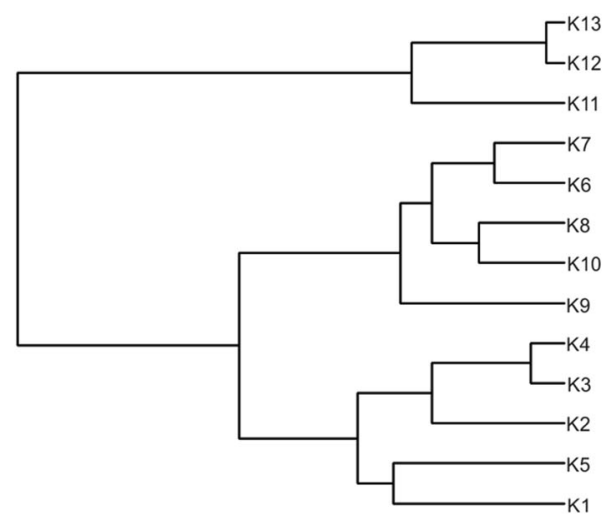

87, Similarity \% 100

(b)

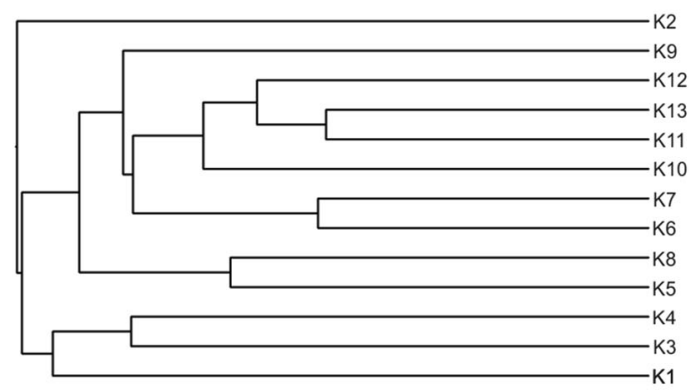

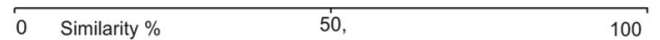

(c)

97, Similarity \% 100

(d)

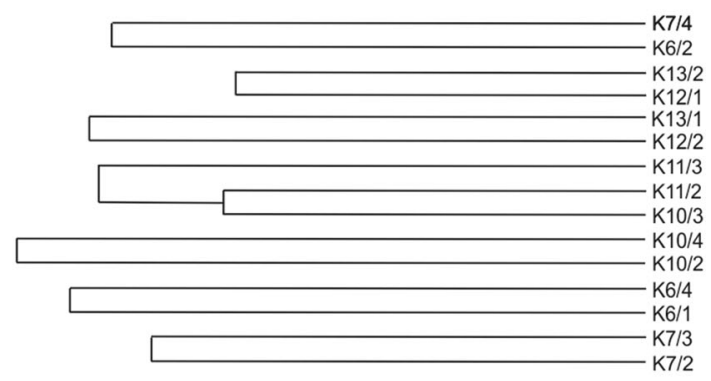

60, \% Similarity

100
4Fig. 3 Similarities of analyzed parameters: a sub-catchment's parameters (landscape level), b water mite assemblages at sampling sites (macrohabitat level), c physical and chemical parameters (macrohabitat level) and d water mite assemblages at sub-sites (mesohabitat level)

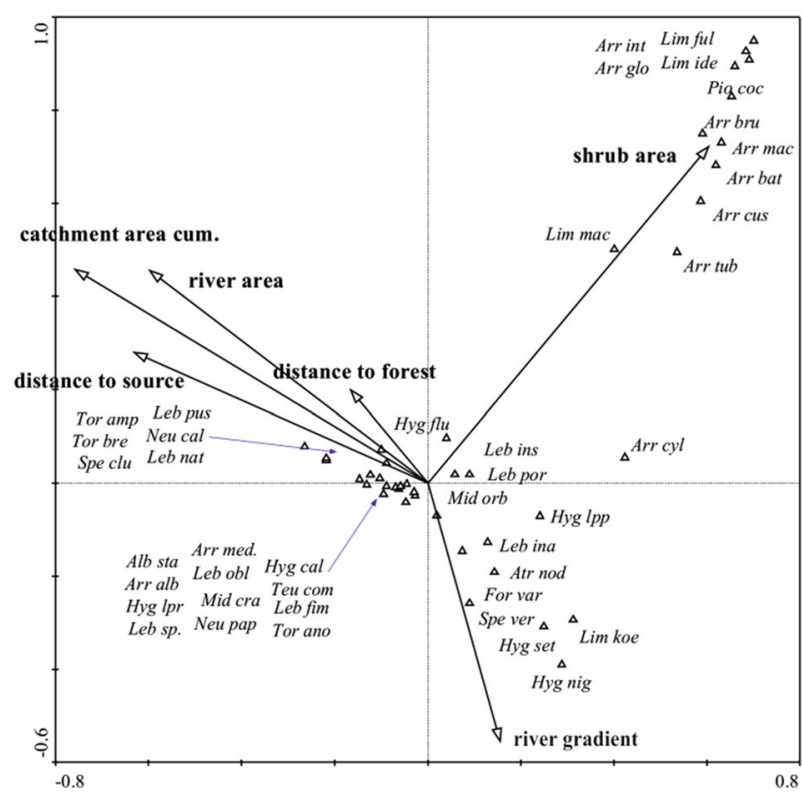

Fig. 4 CCA diagram displaying the relationship between the composition of water mite fauna and different sub-catchment parameters (see Online Resource 2 for full names of species)

(mesohabitats K10/1, 2 and K10/4) (Online Resources 1 and 2 in the ESM). At the opposite pole are species associated with a fine substrate $(M)$. In the upper right-hand corner of the diagram we can see a group of species whose distribution in the river depended on a group of co-occurring factors-plants, organic substrate and insolation, of which the most important factor was plants (Fig. 6). A bottom covered with macrophytes was mainly associated with stagnobiontic species of the genera Limnesia, Piona and Arrenurus.

\section{Discussion}

Several studies show that the structure of macroinvertebrate assemblages in aquatic ecosystems is determined not only by factors acting within the aquatic environment but also by factors acting on a larger spatial scale, outside of the aquatic environment. Weigel et al. (2003) found that assemblages of aquatic macroinvertebrates, at the catchment scale, were shaped by the percentage of forest cover, catchment size, groundwater delivery, percentage of wetland cover and geographical sampling location. Epele et al. (2012) found that land-use practices may have significant 
Table 3 Values for selected statistical data for macrohabitat and mesohabitat levels

\begin{tabular}{llll}
\hline $\begin{array}{l}\text { Level of } \\
\text { analyses }\end{array}$ & $\begin{array}{l}\text { Range of values of faunistic similarities } \\
\text { (in \%) }\end{array}$ & $\begin{array}{l}\text { Range of values of correlation } \\
\text { coefficients }\end{array}$ & $\begin{array}{l}\text { Percentage of correlations statistically } \\
\text { significant }\end{array}$ \\
\hline $\begin{array}{l}\text { Macrohabitat } \\
\text { level }\end{array}$ & $0.0-49.03$ & -0.25 to +0.27 & 14.44 \\
$\begin{array}{l}\text { Mesohabitat } \\
\text { level }\end{array}$ & $0.0-73.93$ & -0.39 to +0.49 & 24.41 \\
\hline
\end{tabular}

Macrohabitat level: faunistic similarities between sampling sites; correlations: between water mite fauna and physicochemical parameters (11 parameters listed in Table 1)

Mesohabitat level: faunistic similarities between sub-sites; correlation: between water mite fauna and environmental parameters measured at the mesohabitat level (7 parameters listed in Table 1)

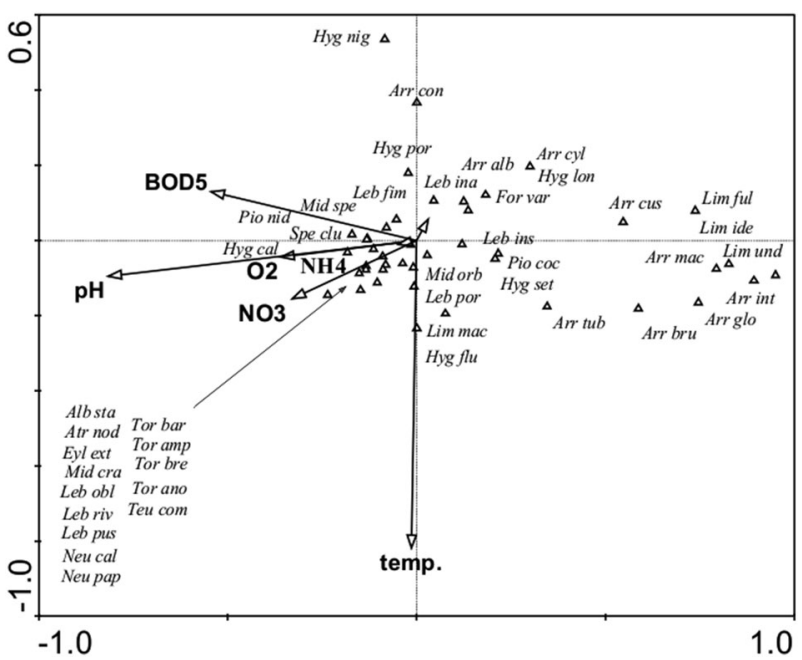

Fig. 5 The CCA diagram displaying the relationships between the composition of water mite fauna and different physical and chemical parameters of the water (only statistically significant correlations/parameters are shown). See Online Resource 2 for full names of species

effects on ecological stream attributes such as increased turbidity, sediment deposition and runoff patterns, which can alter assemblages of Chironomidae inhabiting an aquatic environment. The results of a study by Miserendino and Masi (2010) confirm that macroinvertebrate assemblage structure in Patagonian low-order streams can be altered by land-use practices. Miserendino et al. (2011) found a relationship between land-use intensity and water quality, stream habitat and biodiversity, which in consequence affects aquatic macroinvertebrate assemblages. Stryjecki et al. (2016) found that certain landscape parameters as well as spatial arrangement of the water bodies in the landscape had a strong influence on species composition and abundance of water mite fauna.

Comparison of the similarities between the sub-catchments of individual sites (Fig. 3a) and the similarities of fauna from individual sites (Fig. 3b) shows a similar pattern of cluster formation. The similar grouping of sub-

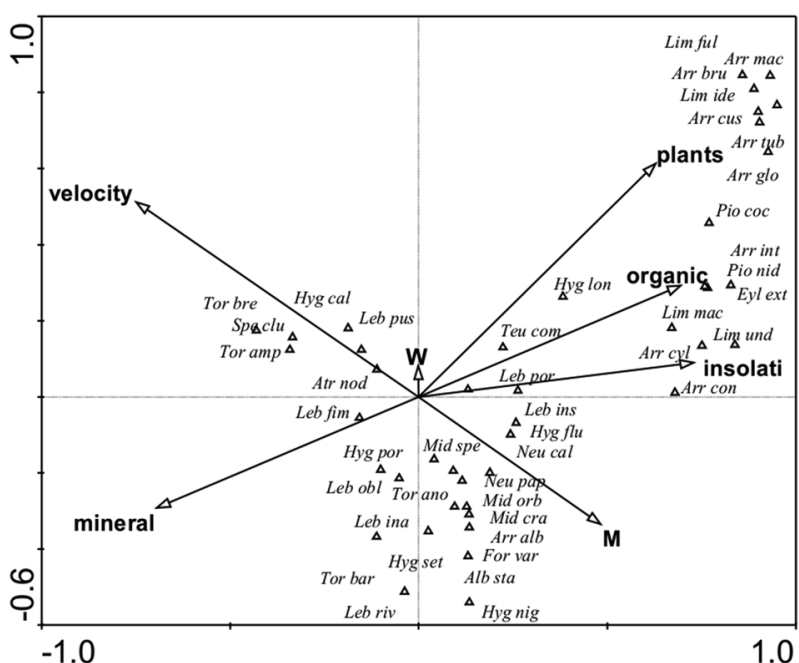

Fig. 6 The CCA diagram displaying the relationships between the composition of water mite fauna and different biotic and abiotic environmental parameters. Mineral mineral sediments, organic organic sediments, $M$ mean sediment grain size, $W$ sediment sorting. See Online Resource 2 for full names of species

catchment and faunal parameters may indicate a cause-andeffect relationship between the landscape and macrohabitat levels. The strongest correlation was noted between certain species of the genera Limnesia, Piona and Arrenurus and the area covered with shrubs in the sub-catchments (Fig. 4). Of course this must be regarded as an indirect link. The group of species grouped around the vector 'shrub area' consists of water mites associated with standing water. These water mites have a parasitic phase in their life cycle; their larvae parasitize terrestrial insects, mainly Chironomidae (Kouwets and Davids 1984; Smith and Oliver 1986), but also Odonata (Biesiadka 2008; Zawal and Buczyński 2013). A likely explanation for this relationship at the landscape scale - between species of the genera Limnesia, Piona and Arrenurus and shrub area-may be the fact that the host insects find better conditions for development in terrain covered with shrubs than in open 
terrain. Delletre and Morvan (2000) found that adults of aquatic chironomids accumulate in higher numbers in wellstructured hedges, which provide the best shelter for insects at rest, while degraded hedges with very low grass cover harbor fewer species and individuals. Some Odonata species also show a predilection for areas covered with shrubs (Balzan 2012). Thus certain groups of insects that are hosts for water mite larvae may be influenced by landscape parameters (e.g., shrub area), and this fact may in turn affect the formation of Hydrachnidia assemblages in the river.

Temperature plays an essential role in shaping water mite assemblages and influences the altitudinal and latitudinal distribution patterns of species (Di Sabatino et al. 2000). Of course, other factors, such as pH, oxygen, electrolyte concentration, trophic conditions and other physicochemical parameters may also play a role in the formation of water mite assemblages (Schwoerbel 1959; Rundle and Hildrew 1990; Smit and van der Hammen 1992; van der Hammen and Smith 1996; Smit and van der Hammen 2000). The Krapiel is a lowland river inhabited by eurythermic species, so it is difficult to identify clear relationships between temperature and the occurrence of particular species. Also, no clear relationship between other physicochemical parameters and the occurrence of particular species was found. As the values for the physicochemical parameters were not extreme (Table 1) and in general within the tolerance ranges for the species recorded (van der Hammen and Smit 1996; Smit and van der Hammen 2000), the lack of a clear relationship between physicochemical properties of water and the faunal composition is unsurprising. Taking into account all factors, the low percentage of physicochemical parameters together in explaining the variance in occurrence of species, the very low values for individual parameters, the very low correlations between species and physicochemical parameters, and the discrepancy in the grouping of sites according to faunal data (Fig. 3b) and the physicochemical parameters (Fig. 3c), we can conclude that factors other than the physical and chemical parameters influence the distribution of fauna in the river.

Of the parameters analyzed at the mesohabitat scale, velocity, plants and insolation had the greatest effect on the occurrence of species. Water current is one of the basic factors influencing the formation of water mite assemblages in lotic ecosystems (Böttger and Martin 1995; van der Hammen and Smit 1996; Martin 1996, 1997). In the fauna of the Krapiel the species most closely associated with this factor were Torrenticola brevirostris, T. amplexa, Sperchon clupeifer, Hygrobates calliger, Lebertia pusilla and Atractides nodipalpis (Fig. 6). As all these species are rheobionts (Böttger and Martin 1995; van der Hammen and Smit 1996; Di Sabatino et al. 2010), it is unsurprising that rapid water flow is a deciding factor influencing their distribution. All these species were caught in the highest numbers in the mesohabitats at site $\mathrm{K} 10$ (K10/1-2), with well-developed lotic zones, but they were also numerous at mesohabitats K11/1-2, K13/1 and K13/4 (Online Resources 1 and 2 in the ESM). Other important factors influencing the distribution of water mites in the Krapiel at the mesohabitat level were insolation and the degree of vegetation cover of the bottom. These factors are obviously correlated: water mites, as heterotrophic organisms, are not dependent on the availability of light, but a bottom covered with macrophytes was mainly associated with the presence of lenitobionts of the genera Limnesia, Piona and Arrenurus (Fig. 6), species characteristic of small, eutrophic and densely overgrown water bodies or the phytolittoral zone of lakes (Biesiadka and Kowalik 1991). In such habitats with slow water flow over organic sediment, the occurrence of species characteristic of standing water bodies is possible. These species were caught mainly in marginal pools and in mesohabitats with well-developed aquatic vegetation, such as K7/2-3 or K8/1-3 (Online Resources 1 and 2 in the ESM). The significant proportion of rheoxenes in lowland river fauna in certain habitats is a natural phenomenon (Böttger and Hoerschelmann 1991; Cichocka 2006; Stryjecki 2009).

In comparison with the macrohabitat level, mesohabitats are characteristic in higher values for faunistic similarity and higher correlations between water mites and several parameters (Table 3). This indicates that factors at the mesohabitat level explain specific water mite assemblages much more precisely than factors acting at the macrohabitat level. For example, when we analyze relationships between water mites and physicochemical parameters (analyses at the macrohabitat level), it is difficult to explain precisely why particular species are arranged on the CCA diagram in this manner (Fig. 5). However, when we take into consideration analyses at the mesohabitat level, it becomes clearer that there are factors other than the physicochemical parameters (mainly water current and plants-factors acting at the mesohabitat level, Fig. 6) that have led to the observed distribution of species. This conclusion, that mesohabitat features are crucial in explaining the synecological structure of the fauna, is supported by other authors, whose studies have shown that the structure of the environment at the mesohabitat level explains the presence of particular taxa because it is an ecological niche for these species (Johnson and Jennings 1998; Weigel et al. 2003; Bonada et al. 2006; Epele et al. 2012; García-Roger et al. 2013). Taking into account all three levels of organization of the environment analyzed in this study, we can conclude that at the landscape level we can find only indirect relationships between environmental factors and the fauna inhabiting the aquatic environment. 
At the macrohabitat level the description of Hydrachnidia is more precise but still of a general nature, and it is only the mesohabitat level that fully explains the structure of Hydrachnidia assemblages (Fig. 1).

Acknowledgements Financial support was provided by the Ministry of Science and Higher Education of Poland, grant no. N305 222537. Reinhard Gerecke (Tübingen) checked and occasionally corrected identification of selected questionable specimens.

Open Access This article is distributed under the terms of the Creative Commons Attribution 4.0 International License (http://crea tivecommons.org/licenses/by/4.0/), which permits unrestricted use, distribution, and reproduction in any medium, provided you give appropriate credit to the original author(s) and the source, provide a link to the Creative Commons license, and indicate if changes were made.

\section{References}

Armitage PD, Prado I (1995) Impact assessment of regulation at the reach level using macroinvertebrate information from mesohabitats. Regul River 10:147-158

Bagge P (2001) Water mites (Hydrachnidia) of the rivers Teno and Kemi, Finnish Lappland. Norw J Entomol 48:147-152

Balzan MV (2012) Associations of dragonflies (Odonata) to habitat variables within the Maltese Islands: a spatio-temporal approach. J Insect Sci 12:87. doi:10.1673/031.012.8701

Biesiadka E (2008) Warer Mites (Hydrachnidia). In: Bogdanowicz W, Chudzicka E, Pilipiuk I, Skibińska E (eds) Fauna of Polandcharacteristics and check-list of species (in Polish). Muzeum i Instytut Zoologii PAN, Warszawa, pp 149-219

Biesiadka E, Kowalik W (1991) Water mites (Hydracarina) as indicators of trophy and pollution in lakes. In: Dusbabek F, Bukwa V (eds) Modern acarology 1. Academia, Prague, pp 475-482

Bonada N, Rieradevall M, Prat N, Resh VH (2006) Benthic macroinvertebrate assemblages and macrohabitat connectivity in Mediterranean-climate streams of northern California. J N Am Benthol Soc 25:32-43

Böttger K (1976) Types of parasitism by larvae of water mites (Acari: Hydrachnidia). Freshw Biol 6:497-500

Böttger K, Hoerschelmann U (1991) Faunistics and ecology of water mites (Hydrachnidia, Actinedida, Actinotrichia, Acari) of the North German lowland creek Kossau. Limnological studies in Naturschutzgebiet Kossautal (Schlezwig-Holstein) III (in German). Faunistisch-(kologische Mitteilungen 6:219-228

Böttger K, Martin P (1995) Faunistic-ecological investigations into water mites (Hydrachnidia, Acari) of three small streams of the Northern Germany lowland with special emphasis on rheobiont species. Limnological Studies in the nature reserve Kossautal (Schleswig-Holstein) V (in German). Limnologica 25:61-72

Boyací YÖ, Gülle P, Gülle Í (2012) Water mite (Hydrachnidia) fauna of Köprüçay River (Antalya) and its branches. Süleyman Demirel Üniversitesi Fen Bilimleri Enstitüsü Dergisi 16:29-32

Cichocka M (2006) Water mites (Hydrachnidia, Acari) in the running waters of the Masurian Landscape Park. Supplementa ad Acta Hydrobiologica 8:33-53

Cicolani B, Di Sabatino A (1991) Sensitivity of water mites to water pollution. In: Dusbabek F, Bukwa V (eds) Modern acarology, vol 1. Academia, Prague, pp 465-474

Delettre YR (2005) Short-range spatial patterning of terrestrial Chironomidae (Insecta: Diptera) and farmland heterogeneity. Pedobiologia 49:15-27
Delettre YR, Morvan N (2000) Dispersal of adult aquatic Chironomidae (Diptera) in agricultural landscapes. Freshw Biol 44:399-411

Delettre Y, Tréhen P, Grootaert P (1992) Space heterogeneity, space use and short-range dispersal in Diptera: a case study. Landsc Ecol 6:175-181

Di Sabatino A, Gerecke R, Martin P (2000) The biology and ecology of lotic water mites (Hydrachnidia). Freshw Biol 44:47-62

Di Sabatino A, Smit H, Gerecke R, Goldschmidt T, Matsumoto N, Cicolani B (2008) Global diversity of water mites (Acari, Hydrachnidia; Arachnida) in freshwater. Hydrobiologia 595:303-315

Di Sabatino A, Gerecke R, Gledhill T, Smit H (2010). Chelicerata: Acari II. In: Gerecke R (ed) Süßwasserfauna von Mitteleuropa, vol 7/2-2, pp 1-234

Diana M, Allan JD, Infante D (2006) The influence of physical habitat and land use on stream fish assemblages in southeastern Michigan. Am Fish Soc Symp 48:359-374

Dohet A, Ector L, Cauchie H-M, Hoffmann L (2008) Identification of benthic invertebrate and diatom indicator taxa that distinguish different stream types as well as degraded from reference conditions in Luxembourg. Anim Biol 58:419-472

Epele LB, Miserendino ML, Brand C (2012) Does nature and persistence of substrate at a mesohabitat scale matter for Chironomidae assemblages? A study of two perennial mountain streams in Patagonia, Argentina. J Insect Sci 12:68. doi:10.1673/ 031.012 .6801

Galic N, Hengeveld GM, van den Brink PJ, Schmolke A, Thorbek P, Bruns E, Baveco HM (2013) Persistence of aquatic insects across managed landscapes: effects of landscape permeability on re-colonization and population recovery. PLoS One 8(1):e54584. doi:10.1371/journal.pone.0054584

García-Roger EM, Sánchez-Montoya M, Cid N, Erba S, Karaouzas I, Verkaik I, Rieradevall M, Gómez R, Suárez ML, Vidal-Abarca RM, DeMartini D, Buffagni A, Skoulikidis N, Bonada N, Prat N (2013) Spatial scale effects on taxonomic and biological trait diversity of aquatic macroinvertebrates in Mediterranean streams. Fund Appl Limnol 183:89-105

Gerecke R, Schwoerbel J (1991) Water quality and water mites (Acari, Actinedida) in the upper Danube region. In: Dusbabek F, Bukwa V (eds) Modern acarology, vol 1. Academia, Prague, pp 483-491

Goldschmidt T (2016) Water mites (Acari, Hydrachnidia): powerful but widely neglected bioindicators - a review. Neotrop Biodivers 2:12-25

Jenness JS (2004) Calculating landscape surface area from digital elevation models. Wildl Soc B 32:829-839

Johnson BL, Jennings CA (1998) Habitat associations of small fishes around islands in the upper Mississippi River. N Am J Fish Manag 18:327-336

Kouwets FAC, Davids C (1984) The occurrence of chironomid imagines in an area near Utrecht (the Netherlands), and their relations to water mite larvae. Arch Hydrobiol 99:296-317

Martin P (1996) Faunistic and ecological studies on the benthos and water mites (Hydrachnidia, Acari) of two streams of the North German lowland (Ostcholsteinisches hills, Schleswig-Holstein) (in German). Faunistisch-(kologische Mitteilungen 7:153-167

Martin P (1997) Faunistics and substrate preference of water mites (Hydrachnidia, Acari) of two streams characterized by fine mineral substrates in Schleswig-Holstein (in German). Faunistisch-(kologische Mitteilungen 7:221-237

McAleece N, Lambshead PJD, Paterson GLJ (1997) Biodiversity Pro. The Natural History Museum, London

McGarigal K, Marks B (1995) FRAGSTATS: spatial pattern analysis program for quantifying landscape structure. Portland (OR): USDA Forest Service, Pacific Northwest Research Station; General Technical Report PNW-GTR-351 
Merriam-Webster Dictionary (2014) http://www.merriam-webster. com/dictionary/macrohabitat. Accessed 18 Nov 2014

Miserendino ML, Masi IC (2010) The effects of land use on environmental features and functional organization of macroinvertebrate communities in Patagonian low order streams. Ecol Indic 10:311-319

Miserendino ML, Casaux R, Miguel Archangelsky M, Di Prinzio CY, Brand C, Adriana Kutschker AM (2011) Assessing land-use effects on water quality, in-stream habitat, riparian ecosystems and biodiversity in Patagonian northwest streams. Sci Total Environ 409:612-624

Richards C, Host G (1994) Examining land use influences on stream habitats and macroinvertebrates: a GIS approach. Water Resour Bull 30:729-738

Richards C, Johnson LB, Host G (1996) Landscape-scale influences on stream habitats and biota. Can J Fish Aquat Sci 53:295-311

Rundle SD, Hildrew AG (1990) The distribution of micro-arthropods in some southern English streams: the influence of physiochemistry. Freshw Biol 23:411-431

Schwoerbel J (1959) Ecological and zoogeographic studies of water mites (Acari, Hydrachnellae) of the springs and streams in the southern part of Black Forest and its periphery (in German). Arch Hydrobiol Suppl 24:385-546

Smit H, van der Hammen H (1992) Water mites as indicators of natural aquatic ecosystems of the coastal dunes of The Netherlands and northwestern France. Hydrobiologia 231:51-64

Smit H, van der Hammen H (2000) Atlas of the Dutch water mites (Acari: Hydrachnidia) (in Dutch). Nederlandse Faunistische Mededelingen 13:1-266
Smith IM, Oliver DR (1986) The parasitic associations of larval water mites with imaginal aquatic insects, especially Chironomidae. Can Ent 108:1427-1442

Smith IM, Smith BP, Cook DR (2001) Water mites (Hydrachnidia) and other arachnids. In: Thorp JH, Covich AP (eds) Ecology and classification of North American freshwater invertebrates, 2nd edn. Academic Press, San Diego, pp 51-659

Stryjecki R (2009) Water mites (Acari, Hydrachnidia) of the Bug River valley between Włodawa and Kodeń. Teka Kom. Ochr. Kszt. Środ. Przyr.-OL PAN 6:335-344

Stryjecki R, Zawal A, Stępień E, Buczyńska E, Buczyński P, Czachorowski S, Szenejko M, Śmietana P (2016) Water mites (Acari, Hydrachnidia) of water bodies of the Krapiel River valley: interactions in the spatial arrangement of a river valley. Limnology 17:247-261

van der Hammen H, Smit H (1996) The water mites (Acari: Hydrachnidia) of streams in the Netherlands: distribution and ecological aspects on a regional scale. Neth $\mathrm{J}$ Aquat Ecol 30:175-185

Weigel BM, Wang L, Rasmussen PW, Butcher JT, Stewart PM, Simon TP, Wiley MJ (2003) Relative influence of variables at multiple spatial scales on stream macroinvertebrates in the Northern Lakes and Forest ecoregion, U.S.A. Freshw Biol 48:1440-1461

Zawal A, Buczyński P (2013) Parasitism of Odonata by Arrenurus (Acari: Hydrachnidia) larvae in the Lake Świdwie, nature reserve (NW Poland). Acta Parasitol 58:486-495 